of suggested symbols has been circulated in advanceair almanacs, the publication of classical works of astronomy which are untranslated or difficult of access, the sources of error in observations with meridian telescopes and the distribution of fundamental stars for observation to different observatories, co-operation in cinematography of solar prominences to cover longer intervals of time than are available for one observatory, wave-length standards in the laboratory and the solar spectrum, the zero point of photographic magnitude and colour index, problems of stellar statistics and the absorption of light in interstellar space. Reports will be received on the present position of the "Carte du Ciel", of the observations of Eros at the opposition of 1931 and of the observations of radio signals at 71 different observatories in the world scheme of 1933. General discussions will take place in the different special committees on the past and future co-operation in the observations of stellar parallaxes, proper motions, variable stars and novæ, radial velocities, solar phenomena and cometary spectra and magnitudes.

IT seems indicated from the reports that there may be discussions on such questions as the origin and maintenance of stellar energy, the hydrogen content of the sun and stars, the theory of the Fraunhofer lines, the source of the far ultra-violet solar radiation, problems of spectrophotometry (of interest to a wider circle than that of astronomers alone) and instrumental questions such as the use of the Schmidt camera, the aluminizing of mirrors and of pyrex matrices for gratings : the work of Prof. R. W. Wood on these lines suggests the ultimate replacement of prisms by gratings for stellar work. The reports of the committees give clear evidence that the conference will be helpful, stimulating and useful, and there is every reason to expect a good attendance from Europe and America. South Africa has recently rejoined the Union and will be represented. Among the less arduous features of the Congress may be mentioned visits to the Observatory at Saltsjöbaden and to the Planetarium, also an excursion to Uppsala. His Majesty the King of Sweden will give a reception at the Royal Palace. The general secretary of the Union is Prof. J. H. Oort, of the Leyden Observatory.

\section{British Museum (Natural History): Acquisitions}

THE two most important additions to the Mammal Section of the Zoological Department during the present month are the bequest by the late $\mathrm{Mr}$. Norman B. Smith of his collection of Rhodesian, East African, and Sudanese game trophies, and a collection of manımals from South-west Africa presented by Major P. H. G. Powell-Cotton and Mr. Christopher Powell-Cotton. An important addition to the Osteological Section is the skeleton of a Hunter's hartebeest (Damaliscus hunteri) from the Tana Valley. The increasing scarcity of this species makes this specimen of special value; it is the gift of Messrs. Rowland Ward. The Museum has acquired from Lieut.-Colonel F. M. Bailey, who has just vacated the post of British envoy to the Court of Nepal, a large collection of birds made in that country. There is still much to be learnt concerning the distribution of Himalayan birds. Many species found in the Eastern parts do not occur in the Western, and the question as to how far east or west in Nepal they extend will, to a great extent, be solved when Colonel Bailey's collection has been properly examined. A further valuable selection of Swiss minerals, numbering 618 specimens from 59 carefully recorded localities, has been presented to the Department of Mineralogy by Mr. F. N. Asheroft. The Department has purchased a large portion of the oldest meteoric stone, the fall of which is recorded. It fell in 1492 at Ensisheim, Alsace, France. For a long time the meteorite, which originally weighed $236 \mathrm{lb}$., was suspended by a chain from the vault of the choir of the parish church of Ensisheim, Alsace.

\section{Geological Museum : Recent Acquisitions}

AMONG the recent acquisitions of the Geological Museum is a large geological relief model of the London basin, measuring about $10 \mathrm{ft}$. by $5 \mathrm{ft}$. This is constructed on a scale of 1 in. to a mile, vertical heights being exaggerated about six times, and it includes an area extending from Foulness in the east to the Vale of White Horse in the west, and from Baldock in the north to Leith Hill in the south. The model illustrates clearly the main synclinal structure of the London basin, from the chalk rocks of which London draws so much of its water supply. Details of this structure of the solid rocks are accentuated by the colouring of drift and other surface deposits by various shades of stipple superimposed on the solid geology. A second relief model just placed on exhibition illustrates the glacial lakes of Cleveland, on a scale of 1 in. to a mile. This reconstruction, which is based on the work of the late Prof. P. F. Kendall, shows the glaciers, ice-dammed lakes, and drainage system of the Cleveland area at the time of the maximum extension of the Pleistocene icesheets. Among the dioramas recently added to the displays is one of an Anglo.Iranian oil-field, presented by the Anglo-Iranian Oil Co. This is the second experiment in a type of diorama in which the foreground is cut away to a depth of several thousand feet to show the geology. Two diamonds of unusual crystal form from Atian Kama, Akim, Gold Coast, have been given by Mr. G. P. Ashmore. Some five hundred varieties of marble used in decorative work in western Europe are now being exhibited.

\section{The Science Museum}

THE report of the Science Museum for 1937 again directs attention to the urgent need for the rebuilding of the centre block and for the extension of the Library. Four years ago, the Advisory Council estimated that the book-stores would be filled by the end of 1938 and gave a warning that further storage room was essential. The Library is the most valuable of its kind in the country and great use is made of it by those engaged in research, and if it is to perform its functions properly it is necessary that books and periodicals should be arranged so that they can be issued to readers with the least possible delay. 